Pacific Journal of Mathematic 


\title{
RATIOS OF INTERPOLATING BLASCHKE PRODUCTS
}

\author{
Peter W. JONES
}

\begin{abstract}
Every unimodular function on the unit circle can be uniformly approximated by ratios of interpolating Blaschke products. As a consequence, we show that points of the maximal ideal space of $H^{\infty}$ can be separated by interpolating Blaschke products.
\end{abstract}

1. Introduction. Let $\Delta$ denote the open unit disc in $C$ and let $H^{\infty}(\Delta)$ be the Banach algebra of functions bounded and analytic on $\Delta$. A sequence of points $\left\{z_{j}\right\}$ in $\Delta$ is called an interpolating sequence if for every bounded sequence $\left\{\alpha_{j}\right\}$ of complex numbers there is a function $F \in H^{\infty}(\Delta)$ such that

$$
F\left(z_{j}\right)=\alpha_{j}, \quad j=1,2, \cdots .
$$

Lennart Carleson [1] has shown that $\left\{z_{j}\right\}$ is an interpolating sequence if and only if

$$
\inf _{\substack { j \\
\begin{subarray}{c}{k \\
k \neq j{ j \\
\begin{subarray} { c } { k \\
k \neq j } }\end{subarray}} \rho\left(z_{j}, z_{k}\right)>0
$$

Here $\rho$ denotes the pseudo hyperbolic metric; $\rho(w, z)=|(w-z) /(1-\bar{w} z)|$ for $w, z \in \Delta$.

For an arc $I$ on the unit circle $T$ let $|I|$ denote the length of $I$ and let $S(I)$ denote the shadow region of $I, S(I)=\{z \in \Delta:(z /|z|) \in I$, $1-|I|<|z|<1\}$. A positive measure $\mu$ on $\Delta$ is called a Carleson measure if

$$
\sup _{I} \frac{1}{|I|} \mu(S(I))=\|\mu\|_{C}<\infty
$$

where the above supremum is taken over all arcs $I$ of $\boldsymbol{T}$. There is also a characterization of interpolating sequences in terms of Carleson measures. A sequence $\left\{z_{j}\right\}$ is an interpolating sequence if and only if

$$
\inf _{\substack{j \neq k \\ j, k}} \rho\left(z_{j}, z_{k}\right)>0
$$

and

$$
\sum\left(1-\left|z_{j}\right|\right) \hat{o}_{z_{j}} \text { is a Carleson measure , }
$$

where $\delta_{z}$ denotes the Dirac $\delta$ measure at $z$.

A Blaschke product with simple zeros lying on an interpolating sequence is called an interpolating Blaschke product. The purpose 
of this paper is to study ratios of interpolating Blaschke products and then use the information gathered to prove a theorem about the maximal ideal space of $H^{\infty}$. A complex valued function $u$ on $T$ is called unimodular if $\left|u\left(e^{i \theta}\right)\right|=1$ for almost all $\theta$. Our first result asserts that every unimodular function on $\boldsymbol{T}$ can be uniformly approximated by ratios of interpolating Blaschke products. (Recall that every Blaschke product has nontangential boundary values satisfying $\left|B\left(e^{i \theta}\right)\right|=1$ almost everywhere.)

THEOREM 1. If $u$ is a unimodular function on $\boldsymbol{T}$ and $\varepsilon>0$, there are interpolating Blaschke products $B_{1}$ and $B_{2}$ such that

$$
\left\|u-\frac{B_{1}}{B_{2}}\right\|_{\infty}<\varepsilon \text {. }
$$

Theorem 1 is a refined version of a theorem of Douglas and Rudin [5]. They proved Theorem 1 with $B_{1}$ and $B_{2}$ (not necessarily interpolating) Blaschke products. Theorem 1 will be proved in $\S 2$.

Our next result answers a question of John Garnett and Donald Marshall.

THEOREM 2. Interpolating Blaschke products separate the points of the maximal ideal space of $H^{\infty}(\Delta)$.

Theorem 2 follows rather easily from Theorem 1 and known results. The strongest result previously known is Ziskind's theorem [13]: If $m_{1}$ and $m_{2}$ are homomorphisms in the maximal ideal space of $H^{\infty}(\Delta)$ with $m_{1}$ lying on the Silov boundary and $m_{2}$ lying off the Silov boundary, there is an interpolating Blaschke $B$ such that $m_{1}(B) \neq m_{2}(B)$. Theorem 2 will be proved in $\S 3$.

Section 4 will be devoted to some comments and open questions.

The author would like to thank John Garnett for extremely valuable discussions on all aspects of this paper, and Donald Marshall for useful correspondence.

2. Proof of Theorem 1. To prove Theorem 1 it is sufficient to show that for any unimodular function $u$ there are interpolating Blaschke products $B_{1}$ and $B_{2}$ such that

$$
\left\|\arg \left(\frac{U B_{2}}{B_{1}}\right)\right\|_{\infty}<\varepsilon
$$

on $\boldsymbol{T}$. Here we define the function arg by

$$
\arg \left(e^{i(\theta+2 \pi k)}\right)=\theta, \quad-\pi<\theta \leqq \pi, \quad k \in \boldsymbol{Z} .
$$


Our proof of Theorem 1 uses an approximation argument due to A. M. Davie which appears in [4]. The idea of this approximation argument is quite simple. For the rest of this section $\varepsilon>0$ will denote a small positive constant; $\varepsilon \leqq 1 / 10$ will do. Suppose $\alpha$ is a real number, $\varepsilon / 2<\alpha \leqq \pi$, and set $\beta=4 \pi \varepsilon^{3} / \alpha$. Let $r=1-\eta$, where $0<\eta<1$ is a small number, and let $A_{1}$ be the Blaschke product with simple zeros at the points

$$
\left\{r e^{i \theta j}: \theta_{j}=j \beta \eta-\varepsilon^{3} \eta, 0 \leqq j \leqq\left[\frac{2 \pi}{\beta \eta}\right]-1\right\} .
$$

Also let $A_{2}$ be the Blaschke product with simple zeros at the points

$$
\left\{r e^{i \theta_{k}}: \theta_{k}=k \beta \eta-\varepsilon^{3} \eta, 0 \leqq k \leqq\left[\frac{2 \pi}{\beta \eta}\right]-1\right\} .
$$

Then one can check by hand that

$$
\left|\alpha-\arg \frac{A_{1}(x)}{A_{2}(x)}\right|<\frac{\varepsilon}{2}, \quad x \in T,
$$

if $A_{1}$ and $A_{2}$ are first multiplied by suitable unimodular constants. Suppose now that $I$ is a subarc of $T$ and $\eta$ is very small with respect to $|I|$. Let $B_{1}$ and $B_{2}$ be the Blaschke products having simple zeros at $\left\{z: A_{1}(z)=0, z /|z| \in I\right\}$ and $\left\{z: A_{2}(z)=0, z /|z| \in I\right\}$ respectively. Then $\arg B_{1}(x) / B_{2}(x) \approx \alpha$ for most $x$ which lie in $I$ and $\arg B_{1}(x) / B_{2}(x) \approx 0$ for most $x$ which lie off $I$. More precisely, the following lemma holds.

LEMMA 2.1. Suppose $I$ is a subarc of $T$ and $\alpha$ is a real number, $|\alpha| \leqq \pi$. Then if $\varepsilon, \delta, \eta>0$ are three positive numbers, there are finite Blaschke products $A_{1}$ and $A_{2}$ with simple zeros such that

$$
\begin{aligned}
& \left|\left\{x \in I:\left|\alpha-\arg \frac{A_{1}(x)}{A_{2}(x)}\right| \geqq \frac{\varepsilon}{2}\right\}\right|<\eta \\
& \left|\left\{x \notin I:\left|\arg \frac{A_{1}(x)}{A_{2}(x)}\right| \geqq \delta\right\}\right|<\eta \\
& \frac{z}{|z|} \in I \text { if } z \text { is a zero of } A_{1} \text { or } A_{2} \\
& \rho\left(z_{1}, z_{2}\right) \geqq \varepsilon^{3} \text { if } z_{1} \text { and } z_{2} \text { are two zeros } A_{1}\left(A_{2}\right) .
\end{aligned}
$$

Furthermore, there is a positive constant $\gamma_{0}=\gamma_{0}(\varepsilon, \delta, \eta, I)>0$ such that whenever $0<\gamma<\gamma_{0}$ we can choose $A_{1}$ and $A_{2}$ as above so that $1-|z|=\gamma$ for all zeros $z$ of $A_{1}$ and $A_{2}$. 
Proof. This is essentially proved in Lemma 12.3 of [4]. Only (2.2) requires verification. Let $C_{1}$ and $C_{2}$ be the two Blaschke factors given by $C_{1}(z)=c_{1} \cdot(z-z)_{1} /(1-\bar{z})_{1} z, \quad C_{2}(z)=c_{2} \cdot(z-z)_{2} /(1-\bar{z})_{2} z$, where

$$
z_{1}=(1-\gamma) e^{i\left(\theta_{0}-\varepsilon^{3} \gamma\right)}, \quad z_{2}=(1-\gamma) e^{i\left(\theta_{0}+\varepsilon^{3} \gamma\right)},
$$

where $\left|c_{1}\right|=\left|c_{2}\right|=1$ are chosen so that $C_{1}\left(e^{i\left(\theta_{0}+\pi\right)}\right)=C_{2}\left(e^{i\left(\theta_{0}+\pi\right)}\right)$. Then

$$
\left|\arg \frac{C_{2}(x)}{C_{2}(x)}\right| \leqq 10 \varepsilon^{3}\left(1+\frac{\left|x-e^{i \theta_{0}}\right|}{\gamma^{2}}\right)^{-1} .
$$

Since the ratio $A_{1} / A_{2}$ given by the construction in Lemma 12.3 of [6] is a product of factors like $C_{1} / C_{2}$ or $C_{2} / C_{1}$, inequality (2.2) follows from (2.3), (2.4), and (2.5), if all zeros $z$ of $A_{1}$ and $A_{2}$ have modulus $|z|=1-\gamma$ where $\gamma$ is sufficiently small.

Repeating the argument of Lemma $2.1 \mathrm{~N}$ times, we obtain the following lemma.

Lemma 2.2. Suppose $I_{1}, I_{2}, \cdots, I_{N}$ are a finite number of disjoint subarcs of $\boldsymbol{T}$ and $\alpha_{1}, \cdots, \alpha_{N}$ are $N$ real numbers, $\left|\alpha_{j}\right| \leqq \pi, 1 \leqq j \leqq N$. Then if $\varepsilon, \delta, \eta>0$ are three positive numbers, there are Blaschke products $A_{1}$ and $A_{2}$ with simple zeros such that

$$
\begin{aligned}
& \left|\left\{x \in I_{j}:\left|\alpha_{j}-\arg \frac{A_{1}(x)}{A_{2}(x)}\right| \geqq \frac{\varepsilon}{2}\right\}\right|<\frac{\eta}{4 N}, \quad 1 \leqq j \leqq N . \\
& \left|\left\{x \notin \bigcup_{j=1}^{N} I_{j}:\left|\arg \frac{A_{1}(x)}{A_{2}(x)}\right| \geqq \delta\right\}\right|<\frac{\eta}{4}, \\
& \frac{z}{|z|} \in \bigcup_{j=1}^{N} I_{j} \text { if } z \text { is a zero of } A_{1} \text { or } A_{2} . \\
& \rho\left(z_{1}, z_{2}\right) \geqq \varepsilon^{3} \text { if } z_{1} \text { and } z_{2} \text { are two zeros of } A_{1}\left(A_{2}\right) .
\end{aligned}
$$

Furthermore, there is a positive constant $\gamma_{0}=\gamma_{0}\left(\varepsilon, \delta, \eta, I_{1}, \cdots, I_{N}\right)>0$ such that whenever $0<\gamma<\gamma_{0}$ we can choose $A_{1}$ and $A_{2}$ as above so that $1-|z|=\gamma$ for all zeros $z$ of $A_{1}$ and $A_{2}$.

We now construct the Blaschke products $B_{1}$ and $B_{2}$ of Theorem 1. Let $u$ be the unimodular function in the statement of the theorem and at stage one put $v_{1}=\arg u$. Then $\left\|v_{1}\right\|_{\infty} \leqq \pi$. Let $\eta_{-1}=2 \pi, \eta_{0}=1$, and let $E_{1}=\left\{x:\left|v_{1}(x)\right| \geqq \varepsilon\right\}$. Find $\delta_{1}>0$ such that

$$
\left|\left\{x: \varepsilon-\delta_{1} \leqq\left|v_{1}(x)\right|<\varepsilon\right\}\right|<\frac{\eta_{0}}{4}=\frac{1}{4} .
$$


Find also a finite collection of disjoint subares of $T, I_{1}^{1}, I_{2}^{1}, \cdots, I_{N}^{1}$, and $N_{1}$ real numbers $\alpha_{1}, \alpha_{2}, \cdots, \alpha_{N_{1}},\left|\alpha_{j}\right| \leqq \pi, 1 \leqq j \leqq N_{1}$, such that

$$
\left|\left\{x:\left|v_{1}(x) \chi_{E_{1}}(x)-\sum_{j=1}^{N_{1}} \alpha_{j} \chi_{X_{j}^{1}}(x)\right| \geqq \frac{\varepsilon}{4}\right\}\right|<\frac{\eta_{0}}{4}=\frac{1}{4} \text {. }
$$

Applying Lemma 2.2 with $\delta=\delta_{1}$ and $\eta=\eta_{0}=1$, we can find finite Blaschke products $A_{1,1}$ and $A_{2,1}$ with simple zeros such that

$$
\left|\left\{x:\left|v_{1}(x)-\arg \frac{A_{1,1}(x)}{A_{2,1}(x)}\right| \geqq \varepsilon\right\}\right|<\eta_{0}=1 .
$$

If $z$ is a zero of $A_{1,1}$ or $A_{2,1}$ then $z /|z| \in \bigcup_{j=1}^{N_{1}} I_{j}^{\prime}$. If $z_{1}$ and $z_{2}$ are two zeros of $A_{1}\left(A_{2}\right)$ then

$$
\rho\left(z_{1}, z_{2}\right) \geqq \varepsilon^{3} .
$$

Furthermore we may choose $A_{1,1}$ and $A_{2,1}$ so that $1-|z|=\eta_{1}$ whenever $z$ is a zero of $A_{1,1}$ or $A_{2,1}$, and we may choose $\eta_{1} \leqq \eta_{0} / 4=1 / 4$. The Blaschke product $A_{1,1}$, satisfies

$$
\sum_{A_{1}, 1(z)=0}(1-|z|) \leqq \eta_{-1} \varepsilon^{-3}=2 \pi \varepsilon^{-3} .
$$

$A_{2,1}$ satisfies a similar inequality.

At stage two set

$$
v_{2}(x)=\arg \left\{u(x) \frac{A_{2,1}(x)}{A_{1,1}(x)}\right\}
$$

and let $E_{2}=\left\{x:\left|v_{2}(x)\right| \geqq \varepsilon\right\}$. Find $\delta_{2}>0$ such that

$$
\left|\left\{x: \varepsilon-\delta_{2} \leqq\left|v_{2}(x)\right|<\varepsilon\right\}\right|<\frac{\eta_{1}}{4} .
$$

Find also a finite collection of disjoint subarcs of $T, I_{1}^{2}, I_{2}^{2}, \cdots, I_{N_{2}}^{2}$, and $N_{2}$ real numbers $\alpha_{1}, \alpha_{2}, \cdots, \alpha_{N_{2}},\left|\alpha_{j}\right| \leqq \pi, 1 \leqq j \leqq N_{2}$, such that

$$
\left|\left\{x:\left|v_{2}(x) \chi_{E_{2}}(x)-\sum_{j=1}^{N_{2}} \alpha_{j} \chi_{I_{j}^{2}}(x)\right| \geqq \frac{\varepsilon}{4}\right\}\right|<\frac{\eta_{1}}{4} \text {. }
$$

Since $\left|\left\{x:\left|v_{2}(x)\right| \geqq \varepsilon\right\}\right|<\eta_{0}=1$, we can pick our intervals so that

$$
\sum_{j=1}^{N_{2}}\left|I_{j}^{2}\right|<\eta_{0}=1 \text {. }
$$

Applying Lemma 2.2 with $\delta=\delta_{2}$ and $\eta=\eta_{1}$, we can find Blaschke products $A_{1,2}$ and $A_{2,2}$ with simple zeros such that

$$
\left|\left\{x:\left|v_{2}(x)-\arg \frac{A_{1,2}(x)}{A_{2,2}(x)}\right| \geqq \varepsilon\right\}\right|<\eta_{1} .
$$


If $z$ is a zero of $A_{1,2}$ or $A_{2,2}$ then $z /|z| \in \bigcup_{j=1}^{N_{2}} I_{j}^{2}$. If $z_{1}$ and $z_{2}$ are two zeros of $A_{1,2}\left(A_{2,2}\right)$ then

$$
\rho\left(z_{1}, z_{2}\right) \geqq \varepsilon^{3} .
$$

Therefore $A_{1,2}$ satisfies

$$
\sum_{A_{1}, 2(z)=0}(1-|z|) \leqq \eta_{0} \varepsilon^{-3}=\varepsilon^{-3},
$$

and $A_{2,2}$ satisfies a similar inequality. We may choose $A_{1,2}$ and $A_{2,2}$ so that $1-|z|=\eta_{2}$ whenever $z$ is a zero of $A_{1,2}$ or $A_{2,2}$, and we may choose $\eta_{2} \leqq \eta_{1} / 4$.

Suppose by induction that we have found Blaschke products with simple zeros $A_{1,1}, A_{1,2}, \cdots, A_{1, n-1}$ and $A_{2,1}, A_{2,2}, \cdots, A_{2, n-1}$ having the following properties. If $z$ is a zero of $A_{1, k}$ or $A_{2, k}$ then

$$
1-|z|=\eta_{k} \leqq \frac{\eta_{k-1}}{4}, \quad 1 \leqq k \leqq n-1 .
$$

If $z_{1}$ and $z_{2}$ are two zeros of $A_{1, k}\left(A_{2, k}\right)$ then

$$
\rho\left(z_{1}, z_{2}\right) \geqq \varepsilon^{3} \text {. }
$$

The zeros of $A_{1, k}$ satisfy

$$
\sum_{A_{1}, k(z)=0}(1-|z|)<\eta_{k-2} \varepsilon^{-3}, \quad 1 \leqq k \leqq n-1,
$$

and $A_{2, k}$ satisfies a similar inequality. If $B_{1, k}=\prod_{j=1}^{k} A_{1, j}, B_{2, k}=$ $\Pi_{j=1}^{k} A_{2, j}$ and $v_{k+1}=\arg \left\{u \cdot\left(B_{2, k} / B_{1, k}\right)\right\}$ then

$$
\left|\left\{x:\left|v_{k+1}(x)\right| \geqq \varepsilon\right\}\right|<\eta_{k-1}, \quad 1 \leqq k \leqq n-1 .
$$

At stage $n$ let $E_{n}=\left\{x:\left|v_{n}(x)\right| \geqq \varepsilon\right\}$. Find $\delta_{n}>0$ such that

$$
\left|\left\{x: \varepsilon-\delta_{n} \leqq\left|v_{n}(x)\right|<\varepsilon\right\}\right|<\frac{\eta_{n-1}}{4} .
$$

Find also a finite collection of disjoint subarcs of $T, I_{1}^{n}, I_{2}^{n}, \cdots, I_{N_{n}}^{n}$, and $N_{n}$ real numbers $\alpha_{1}, \alpha_{2}, \cdots, \alpha_{N_{n}},\left|\alpha_{j}\right| \leqq \pi, 1 \leqq j \leqq N_{n}$, such that

$$
\left|\left\{x:\left|v_{n}(x) \chi_{E_{n}}(x)-\sum_{j=1}^{N_{n}} \alpha_{j} \chi_{I_{j}^{n}}(x)\right| \geqq \frac{\varepsilon}{4}\right\}\right|<\frac{\eta_{n-1}}{4} .
$$

Since $\left|E_{n}\right|<\eta_{n-2}$ by the induction hypothesis, we can pick our intervals so that

$$
\sum_{j=1}^{N_{2}}\left|I_{j}^{n}\right|<\eta_{n-2} .
$$

Applying Lemma 2.2 with $\delta=\delta_{n}$ and $\eta=\eta_{n-1}$, we can find Blaschke products $A_{1, n}$ and $A_{2, n}$ with simple zeros such that 


$$
\left|\left\{x:\left|v_{n}(x)-\arg \frac{A_{1, n}(x)}{A_{2, n}(x)}\right| \geqq \varepsilon\right\}\right|<\eta_{n-1} .
$$

If $x$ is a zero of $A_{1, n}$ or $A_{2, n}$ then $z /|z| \in \bigcup_{j=1}^{N} I_{j}^{n}$. If $z_{1}$ and $z_{2}$ are two zeros of $A_{1, n}\left(A_{2, n}\right)$ then

$$
\rho\left(z_{1}, z_{2}\right) \geqq \varepsilon^{3} .
$$

Therefore $A_{1, n}$ satisfies

$$
\sum_{A_{1, n}(z)=0}(1-|z|) \leqq \eta_{n-2} \varepsilon^{-3},
$$

and $A_{2, n}$ satisfies a similar inequality. We may choose $A_{1, n}$ and $A_{2, n}$ so that $1-|z|=\eta_{n}$ whenever $z$ is a zero of $A_{1, n}$ or $A_{2, n}$, and we may choose $\eta_{n} \leqq \eta_{n-1} / 4$.

Working formally for a moment, put $B_{1}=\prod_{k=1}^{\infty} A_{1, k}, \quad B_{2}=$ $\prod_{k=1}^{\infty} A_{2, k}$. Let $\left\{z_{1, j}\right\}=\left\{z: A_{1, k}(z)=0\right.$ for some $\left.k \geqq 1\right\}$ and let $\left\{z_{2, j}\right\}=$ $\left\{z: A_{2, k}(z)=0\right.$ for some $\left.k \geqq 1\right\}$. Notice that by (2.10) every point in $\left\{z_{1, j}\right\}$ or $\left\{z_{2, j}\right\}$ appears with multiplicity one. Suppose we know that $\left\{z_{1, j}\right\}$ and $\left\{z_{2, j}\right\}$ are interpolating sequences. Then $\left\{z_{1, j}\right\}$ and $\left\{z_{2, j}\right\}$ are Blaschke sequences and the partial products in the definition of $B_{1}$ and $B_{2}$ converge to interpolating Blaschke products. Inequality (2.13) then shows that

$$
\left\|\arg u-\arg \frac{B_{1}}{B_{2}}\right\|_{\infty} \leqq \varepsilon
$$

We now verify that $\left\{z_{1, j}\right\}$ is an interpolating sequence. The proof for $\left\{z_{2, j}\right\}$ is exactly the same. If $k \neq j$, inequalities (2.10) and (2.11) show

$$
\rho\left(z_{1, j}, z_{1, k}\right) \geqq \varepsilon^{3} .
$$

To show that $\mu=\sum\left(1-\left|z_{1, j}\right|\right) \delta_{z_{1, j}}$ is a Carleson measure, it is only necessary to verify the Carleson condition for arcs $I$ of length $2 \eta_{n}$, $n \geqq 1$. So suppose $|I|=2 \eta_{n}$. Then by (2.11),

$$
\sum_{\substack{z_{1} \cdot \dot{j} \in \widetilde{T} \\\left(1-\left|z_{1} \cdot j\right|\right)=\eta_{n}}}\left(1-\left|z_{1, j}\right|\right) \leqq 2 \varepsilon^{-3}|I|
$$

and

$$
\sum_{\substack{z_{1}, j \in \tilde{I} \\\left(1-\left|z_{1}, j\right|\right)=\eta_{n+1}}}\left(1-\left|z_{1, j}\right|\right) \leqq 2 \varepsilon^{-3}|I| .
$$

If $k \geqq 2$, then by (2.10) and (2.12),

$$
\sum_{\substack{z_{1}, j \in \tilde{I} \\\left(1-\left|z_{1}, j\right|\right)=\eta_{n+k}}}\left(1-\left|z_{1, j}\right|\right) \leqq \eta_{n+k-2} \varepsilon^{-3}
$$




$$
\begin{aligned}
& \leqq \eta_{n} \varepsilon^{-3} 4^{2-k} \\
& =8 \varepsilon^{-3} 4^{-k}|I| .
\end{aligned}
$$

Summing on $k \geqq 2$ we obtain

$$
\sum_{z_{1}, j \in \tilde{I}}\left(1-\left|z_{1, j}\right|\right) \leqq 5 \varepsilon^{-3}|I|
$$

so $\sum\left(1-\left|z_{1, j}\right|\right) \delta_{z_{1, j}}$ is a Carleson measure. The proof of Theorem 1 is complete.

3. Proof of Theorem 2. The maximal ideal space of $H^{\infty}, \mathscr{M}_{H^{\infty}}$, is divided into three disjoint parts, which we denote by w, $G$, and $H$. $w$ is the Šilov boundary of $H^{\infty}$. See [5] for properties of $w$. $G$ is the set of all homomorphisms which lie in the closure (in the topology of $\left.\mathscr{C}_{H^{\infty}}\right)$ of an interpolating sequence in the disk. $H$ is the set of homomorphisms which lie in neither $w$ nor $G$. To study $H$ we will have need of $\mathrm{L}$. Carleson's corona theorem [2]:

If $m \in \mathscr{M}_{H^{\infty}}$ then there is a net $\left\{z_{\alpha}\right\}$ of points lying in the unit disk which converge to $m$ in the topology of $\mathscr{A}_{H^{\infty}}$.

Let $m_{1} \neq m_{2}$ be two homomorphisms in $\mathscr{A}_{H^{\infty}}$. To separate $m_{1}$ and $m_{2}$ by an interpolating Blaschke product there are four cases we must treat.

Case I. Either $m_{1} \in G$ or $m_{2} \in G$. Let us suppose $m_{1} \in G$. Then there is an interpolating sequence $\left\{z_{j}\right\}$ such that $m_{1}$ is in the closure of the points $\left\{z_{j}\right\}$, but $m_{2}$ is not. If $B$ is the interpolating Blaschke product with simple zeros at the points $\left\{z_{j}\right\}$, then $m_{1}(B)=0$ and $m_{2}(B) \neq 0$.

Case II. $m_{1} \in \omega$ and $m_{2} \notin ш$. This case has been treated previously by Ziskind [13]. Theorem 1 can also be used to treat this case. There is a Blaschke product $B$ such that $m_{1}(B)=1$ and $m_{2}(B)=0$. (See e.g., [7].) Let $B_{1}$ and $B_{2}$ be two interpolating Blaschke products such that

$$
\left\|B-\frac{B_{1}}{B_{2}}\right\|_{\infty}=\left\|B B_{2}-B_{1}\right\|_{\infty}<\frac{1}{2} .
$$

Then $\left|m_{2}\left(B_{1}\right)\right|=\left|m_{2}\left(B_{1}-B B_{2}\right)\right|<1 / 2$. On the other hand, $\left|m_{1}\left(B_{1}\right)\right|=1$ because $m_{1} \in \omega$.

Case III. $m_{1}, m_{2} \in H$. By theorem of Hoffman [7], every point of $G$ is a one-point Gleason part. Thus for every $\varepsilon>0$ we can find $f_{\varepsilon} \in H^{\infty},\left\|f_{\varepsilon}\right\|_{\infty}=1$, such that $m_{1}\left(f_{\varepsilon}\right)=0$ and $\left|m_{2}\left(f_{\varepsilon}\right)\right|>1-\varepsilon$. The unit ball of $H^{\infty}$ is the norm closed convex hull of the Blaschke 
products [10], so we can find an inner function $u_{\varepsilon}$ such that $m_{1}\left(u_{\varepsilon}\right)=0$ and $\left|m_{2}(u)\right|>1-\varepsilon$. We now invoke a theorem of Ziskind [13].

THEOREM. (Ziskind) Let $u$ be an inner function. There are universal constants $0<\varepsilon_{0}<1, c_{1}$, and $c_{2}$, and there is an interpolating Blaschke product $B$ such that

$$
\begin{aligned}
& \text { if }|u(z)| \leqq \frac{1}{10} \text { then }|B(z)| \leqq \frac{1}{10} . \\
& \text { if } B(z)=0 \text { then }|u(z)| \leqq 1-\varepsilon_{0} . \\
& \rho\left(z_{1}, z_{2}\right) \geqq c_{1} \text { whenever } z_{1} \text { and } z_{2} \text { are two zeros of } B . \\
& \sum_{\substack{B\left(z_{j}\right)=0 \\
z_{j} \in \tilde{I}}}\left(1-\left|z_{j}\right|\right) \leqq c_{2}|I| \text { for all subarcs } I \text { of } T \text {. }
\end{aligned}
$$

For each $\varepsilon>0$ find $B_{\varepsilon}$ as in Ziskind's theorem, corresponding to the inner function $u_{\varepsilon}$. For a set $E \subset \Delta$ define $E^{*} \subset \boldsymbol{T}$ by

$E^{*}=\left\{e^{i \theta}: \mathrm{re}^{i \theta_{0}} \in E\right.$ for some $r$ and $\left.\theta_{0},\left|\theta-\theta_{0}\right| \leqq 1-r\right\} . \quad E^{*}$ is the nontangential projection of $E$ onto $\boldsymbol{T}$.

Now fix $\varepsilon>0$. There are nets $\left\{w_{\alpha}\right\}$ and $\left\{z_{\beta}\right\}$ of points of $\Delta$ such that

$$
w_{\alpha} \longrightarrow m_{1}
$$

and

$$
z_{\beta} \longrightarrow m_{2} \text {. }
$$

Inequality (3.1) shows $\left|m_{1}\left(B_{\varepsilon}\right)\right| \leqq 1 / 10$. By taking a subnet we can assume that $\left|u_{\varepsilon}\left(z_{\beta}\right)\right|>1-\varepsilon$ for all $\beta$. Let $\tau_{\beta}$ be a Mobius transformation which sends 0 to $z_{\beta}$, and let $v_{\varepsilon, \beta}=u_{\varepsilon} \circ \tau_{\beta}$. Then $\left|v_{\varepsilon, \beta}(0)\right|>$ $1-\varepsilon$. Let $E_{\varepsilon, \beta}=\left\{z:\left|v_{\varepsilon, \beta}(z)\right| \leqq 1-\varepsilon_{0}\right\}$, where $\varepsilon_{0}$ is the constant in Ziskind's theorem. Then

$$
\left|E_{\varepsilon, \beta}^{*}\right| \leqq c_{3}(\varepsilon)
$$

where

$$
c_{3}(\varepsilon) \underset{\varepsilon \rightarrow 0}{\longrightarrow} 0 \text {. }
$$

This is essentially proved in $\S 4$ of [11]. Thus by (3.2)-(3.4),

$$
\left|B_{\varepsilon} \circ \tau_{\beta}(0)\right|=\left|B_{\varepsilon}\left(z_{\beta}\right)\right| \geqq 1-c_{4}(\varepsilon)
$$

where

$$
c_{4}(\varepsilon) \underset{\varepsilon \rightarrow 0}{\longrightarrow} 0
$$


Picking $\varepsilon$ so small that $c_{4}(\varepsilon) \leqq 1 / 2$ we see that $\left|m_{2}(B)\right| \geqq 1 / 2$.

Case IV. $m_{1}, m_{2} \in \omega$. Let $u$ be an inner function such that $m_{1}(u)=1, \quad m_{2}(u)=-1$. By Theorem 1 there are interpolating Blaschke products $B_{1}$ and $B_{2}$ so that $\left\|u-B_{1} / B_{2}\right\|_{\infty} \leqq 1 / 4$. Then

$$
\left|m_{1}\left(B_{2} u\right)-m_{1}\left(B_{1}\right)\right|=\left|m_{1}\left(B_{2}\right)-m_{1}\left(B_{1}\right)\right| \leqq \frac{1}{4}
$$

and

$$
\left|m_{2}\left(B_{2} u\right)-m_{2}\left(B_{1}\right)\right|=\left|m_{2}\left(B_{2}\right)+m_{2}\left(B_{1}\right)\right| \leqq \frac{1}{4} .
$$

If $m_{1}\left(B_{1}\right)=m_{2}\left(B_{1}\right)$ the above inequalities show $m_{1}\left(B_{2}\right) \neq m_{2}\left(B_{2}\right)$. (Since $m_{1}, m_{2} \in \omega,\left|m_{1}(v)\right|=\left|m_{2}(v)\right|=1$ for all inner functions $v$.)

REMARKs 4. We conclude with some remarks and questions. It is possible that Theorem 1 could be derived from the Douglas-Rudin theorem but out attempts at this have been unsuccessful. In particular, a positive answer to the following question would suffice.

Question 1. If $B_{0}$ is a Blaschke product and $\varepsilon>0$, is there an interpolating Blaschke product $B_{1}$ with $\left\|B_{0}-B_{1}\right\|_{\infty}<\varepsilon$ ? One might hope that for a given $B_{0}$ there is a complex number $\alpha,|\alpha|<\varepsilon$, such that $B_{0}+\alpha / 1+\bar{\alpha} B_{0}$ is an interpolating Blaschke product. Unfortunately, this is not the case. Kahane [9] and Piranian [12] have shown that there is a Blaschke product $B$ such that

$$
\left|B^{\prime}(z)\right|=o(1-|z|),
$$

while $B$ has infinitely many zeros. On the other hand, if $B$ is an interpolating Blaschke product with infinitely many zeros,

$$
\left|B^{\prime}(z)\right|=O(1-|z|) .
$$

Theorem 2 shows that the uniform algebra generated by interpolating Blaschke products (call it $J$ ) is large in some sense. A natural question is just how large is $J$ ?

\section{Question 2. Does $J=H^{\infty}$ ?}

We do not even know if $J$ and $H^{\infty}$ have the same maximal ideal space. Note that by Marshall's theorem [10], an affirmative answer to Question 1 would give an affirmative answer to Question 2. By using Theorem 1 and the machinery in [10] one can reduce Question 2 to a problem concerning interpolation of bounded sequences by interpolating Blaschke products. An indication that $J$ might be equal to $H^{\infty}$ comes from the Chang-Marshall theorem [3], [11]. 
Finally, we note that BMO can be related to ratios of interpolating Blaschke products through the results of [8]. Perhaps arguments using BMO could be used to answer Questions 1 and 2.

\section{REFERENCES}

1. L. Carleson, An interpolation problem for bounded analytic functions, Amer. J. Math., 80 (1958), 921-930.

2. - Interpolation by bounded analytic functions and the corona problem, Ann. Math., 76 (1962), 547-559.

3. S. Y. Chang, A Characterization of Douglas subalgebras, Acta Math., 137 (1976), 81-89.

4. A. M. Davie, T. W. Gamelin and J. Garnett, Distance estimates and pointwise bounded density, Trans. Amer. Math. Soc., 175 (1973), 37-68.

5. R. G. Douglas and W. Rudin, Approximation by inner functions, Pacific J. Math., 31 (1969), 313-320.

6. O. Frostman, Potentiel d'équilibre et capacité des ensembles, Lund. Univ. Math. Sem., 3 (1935).

7. K. Hoffman, Bounded analytic functions and Gleason parts, Ann. Math., 86 (1967), 74-111.

8. P. W. Jones, Carleson measures and the Fefferman-Stein decomposition of BMO $(\boldsymbol{R})$, to appear in Ann. Math.

9. J. P. Kahane, Trois notes sur les ensembles parfaits linéaires, Enseign. Math., 15 (1969), 185-192.

10. D. E. Marshall, Blaschke products generate $H^{\circ}$, Bull. Amer. Math. Soc., 82 (1976), 494-496.

11. _ - Subalgebras of $L^{\infty}$ containing $H^{\infty}$, Acta Math., 137 (1976), 91-98.

12. G. Piranian, Two monotonic, singular, uniformly almost smooth functions, Duke Math. J., 33 (1966), 255-262.

13. S. Ziskind, Interpolating sequences and the Shilov boundary of $H^{\infty}(\Delta)$, J. Functional Analysis, 21 (1976), 380-388.

Received September 13, 1979.

The University of Chicago

ChicAgo, IL 60637 



\section{PACIFIC JOURNAL OF MATHEMATICS}

\section{EDITORS}

DONALD BABBITT (Managing Editor)

University of California

Los Angeles, CA 90024

HUGo RossI

University of Utah

Salt Lake City, UT 84112

C. C. MOORE and ANDREW OGG

University of California

Berkeley, CA 94720
J. DugundjI

Department of Mathematics

University of Southern California

Los Angeles, CA 90007

R. FinN and J. Milgram

Stanford University

Stanford, CA 94305

\section{ASSOCIATE EDITORS}
R. ARENS
E. F. BECKENBACH
B. H. NeumanN
F. WOLF
K. YOSHIDA

\section{SUPPORTING INSTITUTIONS}

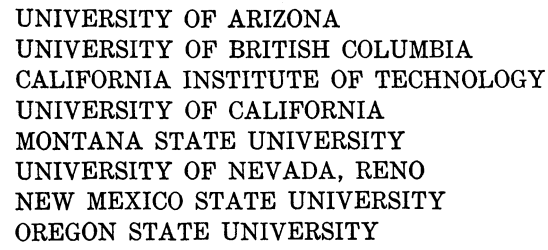

UNIVERSITY OF ARIZONA

UNIVERSITY OF BRITISH COLUMBIA

CALIFORNIA INSTITUTE OF TECHNOLOGY

UNIVERSITY OF CALIFORNIA

MONTANA STATE UNIVERSITY

UNIVERSITY OF NEVADA, RENO

NEW MEXICO STATE UNIVERSITY

OREGON STATE UNIVERSITY

\author{
UNIVERSITY OF OREGON \\ UNIVERSITY OF SOUTHERN CALIFORNIA \\ STANFORD UNIVERSITY \\ UNIVERSITY OF HAWAII \\ UNIVERSITY OF TOKYO \\ UNIVERSITY OF UTAH \\ WASHINGTON STATE UNIVERSITY \\ UNIVERSITY OF WASHINGTON
}

The Supporting Institutions listed above contribute to the cost of publication of this Journal, but they are not owners or publishers and have no responsibility for its content or policies.

Mathematical papers intended for publication in the Pacific Journal of Mathematics should be in typed form or offset-reproduced, (not dittoed), double spaced with large margins. Please do not use built up fractions in the text of the manuscript. However, you may use them in the displayed equations. Underline Greek letters in red, German in green, and script in blue. The first paragraph or two must be capable of being used separately as a synopsis of the entire paper. Please propose a heading for the odd numbered pages of less than 35 characters. Manuscripts, in triplicate, may be sent to any one of the editors. Please classify according to the scheme of Math. Reviews, Index to Vol. 39. Supply name and address of author to whom proofs should be sent. All other communications should be addressed to the managing editor, or Elaine Barth, University of California, Los Angeles, California, 90024.

50 reprints to each author are provided free for each article, only if page charges have been substantially paid. Additional copies may be obtained at cost in multiples of 50 .

The Pacific Journal of Mathematics is issued monthly as of January 1966. Regular subscription rate: $\$ 102.00$ a year (6 Vols., 12 issues). Special rate: $\$ 51.00$ a year to individual members of supporting institutions.

Subscriptions, orders for numbers issued in the last three calendar years, and changes of address shoud be sent to Pacific Journal of Mathematics, P.O. Box 969, Carmel Valley, CA 93924, U.S.A. Old back numbers obtainable from Kraus Per!odicals Co., Route 100, Millwood, NY 10546.

PUBLISHED BY PACIFIC JOURNAL OF MATHEMATICS, A NON-PROFIT CORPORATION

Printed at Kokusai Bunken Insatsusha (International Academic Printing Co., Ltd.). 8-8, 3-chome, Takadanobaba, Shinjuku-ku, Tokyo 160, Japan. 


\section{Pacific Journal of Mathematics}

\section{Vol. 95, No. $2 \quad$ October, 1981}

George E. Andrews, The Rogers-Ramanujan reciprocal and Minc's

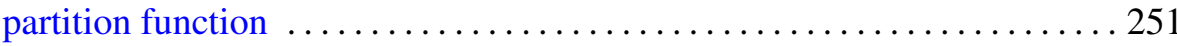

Allan Calder, William H. Julian, Ray Mines, III and Fred Richman,

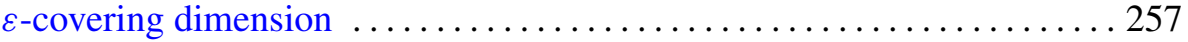

Thomas Curtis Craven and George Leslie Csordas, An inequality for the distribution of zeros of polynomials and entire functions $\ldots \ldots \ldots \ldots 263$

Thomas Jones Enright and R. Parthasarathy, The transfer of invariant

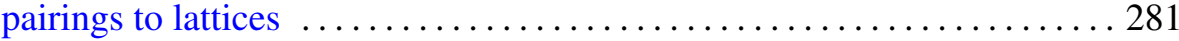

Allen Roy Freedman and John Joseph Sember, Densities and

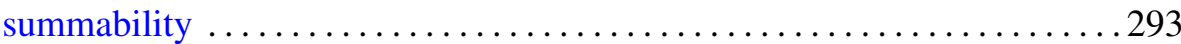

Robert Heller and Francis Aubra Roach, A generalization of a classical necessary condition for convergence of continued fractions . . . . . . 307

Peter Wilcox Jones, Ratios of interpolating Blaschke products ........... 311

V. J. Joseph, Smooth actions of the circle group on exotic spheres ........ 323

Mohd Saeed Khan, Common fixed point theorems for multivalued

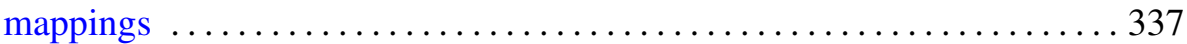

Samuel James Lomonaco, Jr., The homotopy groups of knots. I. How to

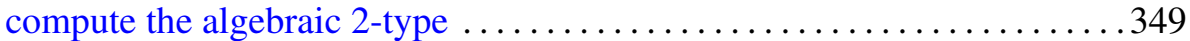

Louis Magnin, Some remarks about $C^{\infty}$ vectors in representations of connected locally compact groups ............................ 391

Mark Mandelker, Located sets on the line . . . . . . . . . . . . . . . . . 401

Murray Angus Marshall and Joseph Lewis Yucas, Linked quaternionic mappings and their associated Witt rings $\ldots \ldots \ldots \ldots \ldots \ldots \ldots \ldots . \ldots \ldots 11$

William Lindall Paschke, $K$-theory for commutants in the Calkin algebra

W. J. Phillips, On the relation $P Q-Q P=-i I$ 435

Ellen Elizabeth Reed, A class of Wallman-type extension. 443

Sungwoo Suh, The space of real parts of algebras of Fourier transforms 461 Antonius Johannes Van Haagen, Finite signed measures on function

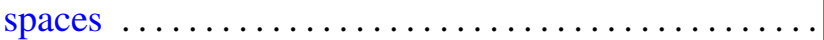

Richard Hawks Warren, Identification spaces and unique uniformity 